\title{
EXTRACTOS METANÓLICOS DE CORTEZA DE GUAYABA (Psidium guajava L.) Y MANGO (Mangifera indica L.): EFECTO CITOTÓXICO, ANTIHEMOLÍTICO Y EN LA MORFOLOGÍA DE MEMBRANA DE ERITROCITOS
}

\section{METHANOLIC EXTRACTS OF GUAVA (Psidium guajava L.) AND MANGO CRUSTS (Mangifera indica L.): CITOTOXIC, ANTIHEMOLITIC EFFECT AND IN THE MORPHOLOGY OF ERYTHROCYTES MEMBRANE}

\author{
Marlene Durán ${ }^{1}$, Piedad Montero $^{2}$, Yesid Marrugo ${ }^{3}$
}

\begin{abstract}
${ }^{1}$ Bacterióloga, Candidata a Doctor en Ciencias, Facultad de Ingeniería, Universidad de Cartagena. Piedra de Bolívar - Av. del Consulado, Calle 30 No. 48-152, Cartagena-Bolívar, Colombia, mduranl@unicartagena.edu.co; marlene_duran@hotmail. es; ${ }^{2}$ Ingeniero de Alimentos, M.Sc., Grupo de Investigación (NUSCA), Facultad de Ingeniería, Universidād de Cartagena, Colombia, pmonteroc@unicartagena.edu.co; pmargaritamontero@hotmail.com; ${ }^{3}$ Ingeniero de Alimentos, M. Sc., Grupo de Investigación (NUSCA), Facultad de Ingeniería, Universidad de Cartagena, Colombia, ymarrugol@unicartagena.edu.co
\end{abstract}

Rev. U.D.C.A Act. \& Div. Cient. 16(2): 327-334, Julio-Diciembre, 2013

\section{RESUMEN}

En la costa caribe, los frutos verdes se consumen con alta frecuencia y, en este proceso, los comerciantes de estos productos eliminan las cortezas como productos de desechos, las cuales, podrían ser aprovechadas en la industria alimentaria y en la mejora del medio ambiente. El objetivo de este estudio fue determinar alteraciones en las membranas biológicas utilizando, como modelo, el eritrocito, la actividad antihemolitica inducida por peróxido de hidrógeno y deformabilidad de la membrana, causada por diferentes concentraciones $(200,100,50$ y $20 \mu \mathrm{g} / \mathrm{mL})$ de los extractos metanólicos total, de cada una de las cortezas de las frutas evaluadas. La citotoxicidad fue realizada utilizando la exclusión de azul de tripano en mononucleares de sangre periférica. La actividad antihemolítica, se determinó por espectrofotometría, a una longitud de onda de 520 $\mathrm{nm}$, la deformabilidad fue realizada por conteo de eritrocitos morfológicamente alterados, específicamente, las formas equinociticas. Los extractos de cortezas de mango y guayaba no fueron citotóxicos a las concentraciones evaluadas, mostraron viabilidad celular superior a $80 \%$. Inhibieron la hemólisis en presencia de $\mathrm{H}_{2} \mathrm{O}_{2}$, el extracto de guayaba a $100 \mu \mathrm{g} / \mathrm{mL}$ registró la mayor inhibición de hemólisis inducida. Los mayores porcentajes de alteración morfológica, se observaron cuando los eritrocitos se expusieron a concentraciones de 100 y $200 \mu \mathrm{g} / \mathrm{Ml}$; en el extracto de corteza de guayaba, la concentración de $200 \mu \mathrm{g} /$
mL mostró $47 \%$ de equinocitos, mientras que el extracto de mango, a $200 \mu \mathrm{g} / \mathrm{mL}$, mostró $90 \%$ de equinocitos.

Palabras clave: Membrana eritrocitaria, extractos, estrés oxidativo, citotoxicidad.

\section{SUMMARY}

In the Caribbean coast green fruits are consumed at high frequency and in this process the traders of these products remove the crusts as waste products, which could be exploited in the food industry and in environmental improvement. The objective of this study was to determine alterations in biological membranes using as a model the erythrocyte, the antihemolytic activity induced by hydrogen peroxide, and the membrane deformability caused by different concentrations (200, 100, 50 and $20 \mathrm{ug} / \mathrm{mL}$ ) of the total methanol extracts of crusts of the tested fruits. The cytotoxicity was performed using the trypan blue exclusion in mononuclear of peripheral blood. Antihemolytic activity was determined by spectrophotometry at a wavelength of $520 \mathrm{~nm}$, the deformability was made by counting erythrocytes morphologically altered specifically equinocyte forms. Extracts of mango and guava crusts were not cytotoxic at the tested concentrations; they showed cell viability higher than $80 \%$. They inhibited the hemolysis in the presence of $\mathrm{H}_{2} \mathrm{O}_{2}$, the guava extract at $100 \mu \mathrm{g} / \mathrm{mL}$ recorded the greatest inhibition of induced hemolysis. Higher percentages 
of morphological changes were observed when erythrocytes were exposed to concentrations of 100 and $200 \mu \mathrm{g} / \mathrm{mL}$. In extract of guava crust the concentration was $200 \mu \mathrm{g} / \mathrm{mL}$, it showed $47 \%$ of echinocyte, whereas mango extract $200 \mu \mathrm{g} /$ $\mathrm{mL}$ showed $90 \%$ of echinocyte.

Key words: Erythrocyte membrane, extracts, oxidative stress, cytotoxicity.

\section{INTRODUCCIÓN}

Los radicales libres son moléculas que, en su estructura, presentan un electrón desapareado o impar, dándole una configuración que genera alta inestabilidad, altamente reactivos, de corta vida y capacidad de combinarse con biomoléculas integrantes de la estructura celular (Rodríguez et al. 2001).

Los radicales libres son producto del metabolismo celular y son inactivados por mecanismos enzimáticos y de atrapamiento; la exposición de la materia viva sometida a un desequilibrio entre sustancia pro-oxidantes y mecanismos antioxidantes, se conoce como estrés o daño oxidativo (Venereo, 2002). La generación de radicales libres están relacionados con muchas enfermedades, de las que no escapan las hematológicas, como la anemia de células falciforme y otras hemoglobinopatías (Grinberg et al. 1997). Las plantas, entre ellas las productoras de frutas, tienen gran importancia, debido al contenido de polifenoles, flavonoides taninos y catequinas, con propiedad antioxidante, gracias a su capacidad de atrapar radicales libres; varios estudios de extractos y pulpas de frutas han reportado actividad antioxidante (Guo et al. 2003; Almeida et al. 2011; Okonogi et al. 2007); sin embargo, existe poca información del potencial antioxidante presente en cortezas de frutas, a menudo consideradas productos de desecho, debido a su falta de aplicación comercial (Soong \& Barlow, 2004).

Colombia es uno de los países con la más grande variedad de frutas, a nivel mundial. Esto es debido a la diversidad geográfica, diferentes clases de suelos y climas, cuenta al menos con 51.220 especies de plantas y flores, al menos 150 tipos de frutas son originarias de Colombia y más de 50 son aclimatadas, procedentes de África, Asia, Eurasia y Australia (Contreras-Calderón et al. 2011).

Las frutas contienen una gran cantidad de nutrientes, como son vitaminas, minerales, fibra dietaría, compuestos fitofenólicos Flavonas, ácido fenólico, cuyos compuestos ayudan a la protección contra las enfermedades degenerativas, como cáncer, enfermedades cardiovasculares, propiedades atribuidas a su alto contenido de diversos antioxidantes (Kaur \& Kapoor, 2001).

Además de nutrientes, las frutas poseen pigmentos y sus- tancias reguladoras del crecimiento y protectores naturales frente a fitopatógenos (Koike et al. 2003). El material de desecho de las frutas está constituido, principalment,e por cáscaras, por semillas y por membranas capilares, a partir de los cuales, se pueden elaborar harinas, pectina cítrica, aceites esenciales, pigmentos y productos especiales, así como también la extracción de compuestos bioactivos, que tienen efectos benéficos sobre la salud, tales como la fibra y los polifenoles, en especial, los flavonoides (Rincón et al. 2005).

En condiciones normales, cuando los eritrocitos son sometidos a estrés oxidativo, el hierro puede ser liberado de la hemoglobina y unirse a metabolitos intracelulares y componentes de la membrana; estos compuestos de hierro pueden reaccionar con oxígeno y generar radicales hidroxilos $(\mathrm{OH}) \mathrm{y}$, en consecuencia, oxidar lípidos de las membranas (peroxidación lipídica) (Suwalsky et al. 2008).

Los eritrocitos (RBC) son un modelo celular utilizado en la investigación de daño oxidativo en las biomembranas (Ugartondo et al. 2006). Fosfolípidos, proteínas transmembrana y colesterol, en combinación con una red de proteínas del citoesqueleto, son responsables de la integridad de la membrana del eritrocito (Smith, 1987). Entre las proteínas que hacen parte del citoesqueleto, se encuentra la espectrina y sus funciones están la regulación, la deformabilidad y la estabilidad de la membrana eritrocitaria (Mohandas et al. 1983). El eritrocito normal tiene forma bicóncava, ausencia de núcleo y un reducido metabolismo; la alteración de la forma básica, se traduce en disminución de sus funciones primordiales, lo que puede significar trastornos graves en el organismo humano. La principal alteración corresponde al equinocito, los cuales, son eritrocitos esféricos con espículas, que son vesículas lipídicas que protruyen desde la membrana (Carrillo-Esper et al. 2012).

La protección que las frutas y los vegetales pueden brindar contra las enfermedades degenerativas, como cáncer y enfermedades cardiovascular, ha sido atribuida a su alto contenido de compuestos antioxidantes (Gardner et al. 2000; Sun et al. 2002). Los compuestos antioxidantes de origen natural, entre ellos compuestos polifenólicos, incrementan la resistencia de los eritrocitos al estrés oxidativo (Ajila \& Prasada, 2008). Los extractos de mango han mostrado protección contra cáncer de próstata en modelos in vivo e in vitro (Prasad et al. 2007). Los extracto de corteza de mango también inhibieron el ciclo celular en fase G0/G1 de células HL-60 (Percival et al. 2006). De otra parte, un estudio in vitro realizado en fibroblastos de Hámster línea B14 muestran correlación con daño y reparación del DNA (Labieniec \& Gabryelak, 2005), por lo tanto, se hace necesario realizar estudios de genotoxicidad en estos subproductos, para demostrar propiedades benéficas, que se pudieran utilizar para el consumo humano. 


\section{MATERIALES Y MÉTODOS}

Obtención del extracto. Los frutos verdes, se obtuvieron de plantaciones locales del municipio de Turbaco (Bolívar); las frutas recolectadas se guardaron en bolsas plásticas para su traslado al laboratorio, las cuales, se guardaron en refrigeración a $4^{\circ} \mathrm{C}$, hasta su procesamiento. Posteriormente, fueron lavados con agua destilada estéril y secados con papel absorbente; luego, se procedió a quitar las cortezas de manera manual. Estas fueron desecadas a $60^{\circ} \mathrm{C}$, por 72 horas; luego de este tratamiento fueron molidas; de este material, se tomó $100 \mathrm{~g}$ y se adicionó $200 \mathrm{~mL}$ de metanol, se dejó en reposo 24 horas, a temperatura ambiente. Después de este tiempo fue filtrada y concentrada a presión reducida, obteniéndose una suspensión acuosa de color pardo, que constituyó el extracto metanólico total EMT (Gaitán et al. 2006).

Obtención de Mononucleares de sangre periférica. La sangre fue obtenida de voluntarios sanos no fumadores y recogida en tubos con heparina, previo consentimiento informado, procedimiento avalado por el comité de ética de la Universidad de Cartagena; los linfocitos, se aislaron con método estándar por centrifugación en gradiente de densidad sobre ficoll histopaque (Histopaque-1077 sigma); luego de separados fueron lavados dos veces, con PBS y resuspendidos en el mismo buffer con glucosa $5 \mathrm{mM}$ y llevados a una suspensión de $10^{6} / \mathrm{mL}$ (Martínez et al. 2007). Estas se dispensaron en placas de 96 pocillos por triplicado, a razón de $100 \mu \mathrm{L}$ por pocillo.

Actividad citotóxica in vitro: Fue evaluado por el método de exclusión de azul de tripano; las células anteriormente dispensadas fueron adicionada de $100 \mu \mathrm{L}$ de los extractos a las concentraciones de $20,40,100 \mu \mathrm{g} / \mathrm{mL}$, que se incubaron por 24 horas, a $37^{\circ} \mathrm{C}$; después de este tiempo fueron tratadas con colorante azul de tripano $0,4 \%$; luego, se realizó el conteo del número de células teñidas en función del total de 500 células, observadas con objetivo de 40X, esto permitió calcular el porcentaje de supervivencia (Strober, 2001; Slameñová et al. 2009). El porcentaje de viabilidad, se evaluó según (Martínez et al. 2007):

$\%$ Viabilidad $=(\#$ de células teñidas/Total de células contadas) $\times 100$

Preparación de la suspensión de eritrocitos: Lo eritrocitos humanos de sangre periférica humana heparinizada, se obtuvieron de individuos sanos, previo consentimiento informado, mediante gradiente de densidades con FicollHipaque (Hystopaque-1077 SIGMA), por centrifugación a 1500rpm, por $5 \mathrm{~min}$, a temperatura ambiente; se recogieron con sumo cuidado, para evitar riesgo de hemólisis, los cuales, se resuspendieron en PBS glucosado y centrifugados a 1600 rpm, por 10 minutos (Pinell et al. 2009).
Actividad hemolítica: La inhibición de la hemólisis inducida por $\mathrm{H}_{2} \mathrm{O}_{2}$ fue evaluado, según el método de Grinberg et al. (1997). Una suspensión de $10 \mu \mathrm{L}$ conteniendo $1 \times 10^{5}$ eritrocitos $/ \mathrm{mL}$ se incubaron en presencia de los extractos de mango y de guayaba, a la concentración de $100 \mu \mathrm{g} / \mathrm{mL}$ e incubados $37^{\circ} \mathrm{C}$, en agitación constante, por 30 minutos, en presencia de $\mathrm{H}_{2} \mathrm{O}_{2} 5 \%$ (v/v); después de este tratamiento, se centrifugó a 10.000 rpm por 10 minutos y el sobrenadante fue usado para medir la hemoglobina liberada. Un blanco de $100 \%$ de hemólisis fue usado $\left(1 \times 10^{5}\right.$ eritrocitos tratado con $\mathrm{H}_{2} \mathrm{O}_{2}$ ). El porcentaje de liberación de hemoglobina fue determinado a una longitud de onda 540nm (Goyal et al. 2012).

Morfologia eritrocitaria: La determinación de la alteración morfológica fue llevada a cabo por microscopia óptica: los eritrocitos fueron separados del plasma y lavados cuatro veces, con buffer fosfato salino (PBS), a pH 7,3 y suspendidos en la misma solución, a un hematocrito del $2 \%$, pero conteniendo de $10-200 \mu \mathrm{g} / \mathrm{mL}$ de los extractos de corteza de mango y de guayaba; estos se mantuvieron 1 hora, a $37^{\circ} \mathrm{C}$; después de este tratamiento, los eritrocitos fueron fijados con una solución de glutaraldehido al $0,2 \%$ y observadas en microscopio óptico, marca Leyca. Se realizó un recuento de las formas básicas equinocitos y estomatocitos en una población de 500 células. Las observaciones se realizaron microscópicamente, con objetivo 100 X (Bonarska-Kujawa et al. 2010).

Diseño estadístico: El diseño experimental utilizado en esta investigación fue un diseño factorial 2 × 4 (8 tratamientos), con tres repeticiones. Los factores fueron el tipo de fruta 0 extracto con dos niveles (guayaba y mango) y la concentración en $\mu \mathrm{g} / \mathrm{mL}$, con cuatros niveles (20, 50, 100 y 200 $\mu \mathrm{g} /$ $\mathrm{mL}$ ). Las variables respuesta fueron la citotoxicidad, deformabilidad y actividad antihemolitica; cada muestra se analizó por triplicado. Los resultados son mostrados como la media \pm desviación estándar (EE). Las diferencias entre las concentraciones de los extractos analizados fueron evaluadas mediante el test de ANOVA y se usó la prueba t-student, para el análisis post-varianza. Para todos los análisis el criterio de significancia fue establecido a $\mathrm{p}<0.05$.

\section{RESULTADOS Y DISCUSIÓN}

En la figura 1, se observa que la viabilidad, mostrada por los extractos de corteza de guayaba y de mango mostró porcentaje de viabilidad superior al $80 \%$ a las concentraciones de 50 y $20 \mu \mathrm{g} / \mathrm{mL}$. Las cortezas de mango mostraron un porcentaje de inhibición de viabilidad en mononucleares de 75, 85, 90 y 95, a las concentraciones de 200, 100, 50 y 20 $\mathrm{g} / \mathrm{mL}$. La viabilidad en mononucleares mostrada por los extractos de cortezas de guayaba verde fue de 85,90 y $95 \%$, a las concentraciones de 200, 100, 50 y $20 \mu \mathrm{g} / \mathrm{mL}$. 


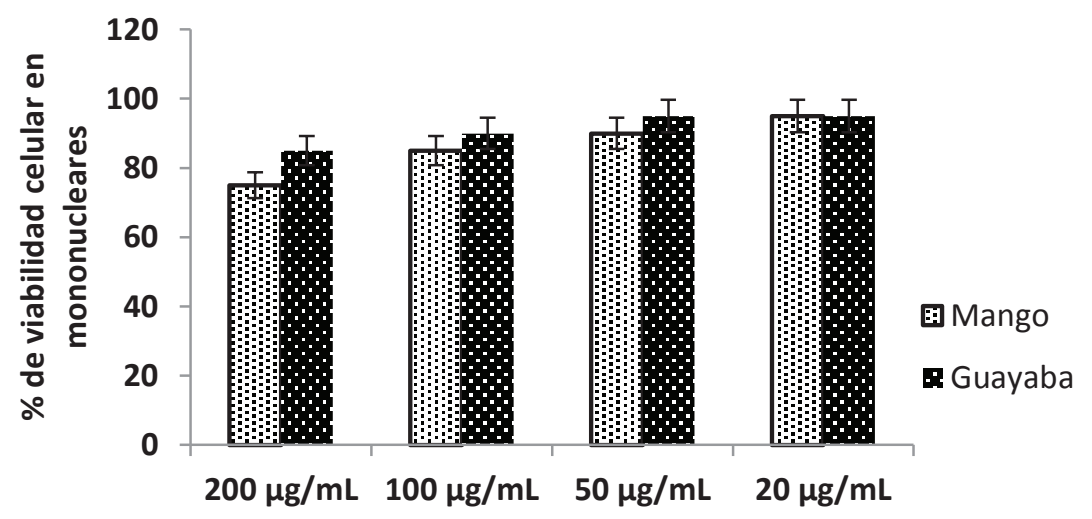

Concentración de los extractos de cortezas de mango y guayaba

Figura 1. Citotoxicidad de los extractos de corteza de mango y de guayaba a las 24 horas de exposición. Los resultados son presentados como la media más o menos la desviación estándar de tres experimentos independientes. p 0,34 no hubo significancia estadística entre los extractos evaluados.

En la figura 2, los extractos mostraron inhibición de hemólisis en los eritrocitos inducida por $\mathrm{H}_{2} \mathrm{O}_{2}$, observándose que los extractos de corteza de guayaba inhibieron la inducción de hemólisis en una proporción de 54,6; 55; 62; 37,7\% a las concentraciones de $20,50,100$, y $200 \mu \mathrm{g} / \mathrm{mL}$, respectivamente, mientras que los extractos de corteza de mango verde mostraron porcentajes de inhibición hemólisis 52, 35, 36 y $20 \%$, a las concentraciones de 20, 50, 100 y $200 \mu \mathrm{g} / \mathrm{mL}$, respectivamente.
Las concentraciones de extractos de cortezas mango y guayaba verdes inhibieron la hemólisis inducida por $\mathrm{H}_{2} \mathrm{O}_{2}$, a concentraciones comprendidas entre $20-200 \mu \mathrm{g} / \mathrm{mL}$, expuestas durante 30 minutos; la menor hemólisis fue de $48 \%$ mostrada por la corteza de mango, a concentración de $20 \mu \mathrm{g} / \mathrm{mL}$, mientras que el extracto de la corteza de guayaba mostró el mismo porcentaje de inhibición de la hemólisis, inducida a las concentraciones de 20 y $40 \mu \mathrm{g} / \mathrm{mL}$, la cual, fue del $45 \%$. La menor inhibición de la hemólisis fue mostrada por el ex-

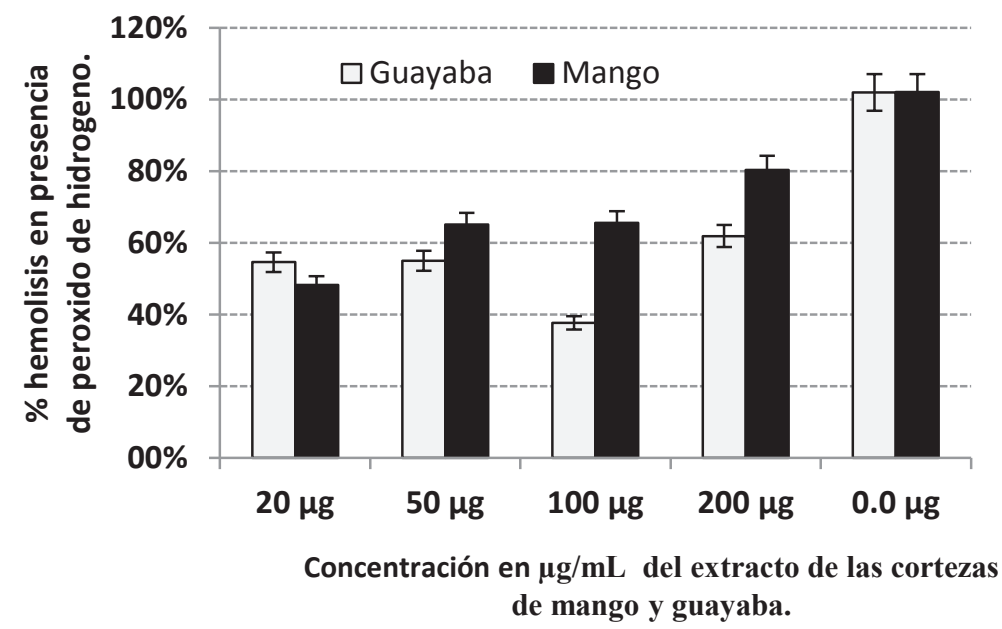

Figura 2. Inhibición de hemólisis en presencia de peróxido de hidrógeno a las diferentes concentraciones de los extractos de las cortezas evaluadas. Los resultados son presentados como la media más o menos la desviación estándar de tres experimentos independientes. p 0,41 no hubo significancia estadística entre los extractos evaluados. 
tracto de la corteza de guayaba a la concentración de $100 \mu \mathrm{g} /$ $\mathrm{mL}$, correspondiente a una inhibición del 63\%; sin embargo, el extracto de corteza de guayaba a $100 \mu \mathrm{g} / \mathrm{mL}$ mostró el menor porcentaje; la comparación de estas concentraciones mostró una p de 0,49 , lo cual, indica que no hubo diferencias estadística significativas.

Un estudio realizado en guayabas mostró un porcentaje de polifenoles, comprendido entre 2 - 8\% (Jiménez-Escrig et al. 2001). Ajila \& Prasada (2008) encontraron polifenoles, antocianinas y carotenoides en los extractos de corteza, compuestos que han mostrado actividad antioxidante. La propiedad antioxidante, se relaciona con la protección de membranas celulares, ya que inhibirían la interacción de los componentes estructurales tipo fosfolípidos inhibiendo su oxidación y protegiendo la misma de daños causados por compuestos oxidantes (García Bacallao et al. 2001).

Se ha establecido que compuestos fenólico abundante en los extractos vegetales es un antioxidante efectivo; a una concentración de $1,2 \times 10^{-5} \mathrm{M}$ e inhibió cerca del $80 \%$ de la formación de peróxido, en un sistema de prueba con ácido linoleico (Chávez et al. 2013). Soong \& Barlow (2004) demostraron que las cáscaras verdes de mango eran ricas en polifenoles (Chen \& Yen, 2007; Wang et al. 2012).

La deformabilidad eritrocitaria, evidenciada por la formación de equinocitos en presencia de los extractos de las cortezas de mango y de guayaba verdes, a concentración de $200 \mu \mathrm{g} /$ $\mathrm{mL}$, la menor deformabilidad fue observada a concentración de $50 \mu \mathrm{g} / \mathrm{mL}$ en ambos extractos (Figura 3).
Los extractos de guayaba mostraron 15, 15, 32 y $47 \%$ de equinocitos, a las concentraciones de 20,50, 100 y 200 $\mathrm{g} /$ $\mathrm{mL}$, respectivamente. Mientras que el extracto de mango mostró porcentajes 25 - 95, a las concentraciones evaluadas (Figura 3).

Con respecto a los cambios observados, a nivel de la membrana del eritrocito, la forma predominante mostrada en este estudio fue el equinocito presentado en ambos extractos (Figura 3). Se sugiere que esta alteración es debida a cambios en el pH. En estudios previos fue demostrado que $\mathrm{pH}$ altos conducen a un cambio de forma discoide normal a equinocitos, mientras que $\mathrm{pH}$ bajos inducen cambios hacia estomatocitos (Gedde et al. 1997). Los resultados obtenidos en esta investigación están de acuerdo con el estudio realizado por Gedde et al. (1997). El porcentaje de equinocitos observados para el extracto de guayaba fue menor del $15 \%$, a las concentraciones de 20 y $50 \mu \mathrm{g} / \mathrm{mL}$, mientras que para las concentraciones mayores, el porcentaje de equinocitos no superó el $50 \%$.

La alteración morfológica observada con el extracto de mango fue similar a la presentada por el extracto de guayaba; el porcentaje de equinocitos fue inferior a las concentraciones de 20 y $50 \mu \mathrm{g} / \mathrm{mL}$, mientras que las concentraciones de $100 \mathrm{y}$ $200 \mu \mathrm{g} / \mathrm{mL}$ mostraron porcentajes de equinocitos, superiores al $50 \%$, pero no alcanzan el $70 \%$. La mayor alteración fue observada a concentración de $200 \mu \mathrm{g} / \mathrm{mL}$, mientras que el menor porcentaje de alteración fue mostrado a concentración de $50 \mu \mathrm{g} / \mathrm{mL}$, en ambos extractos. Algunas sustancias exógenas, tipo detergentes anionicos, benceno, dodecilsulfato

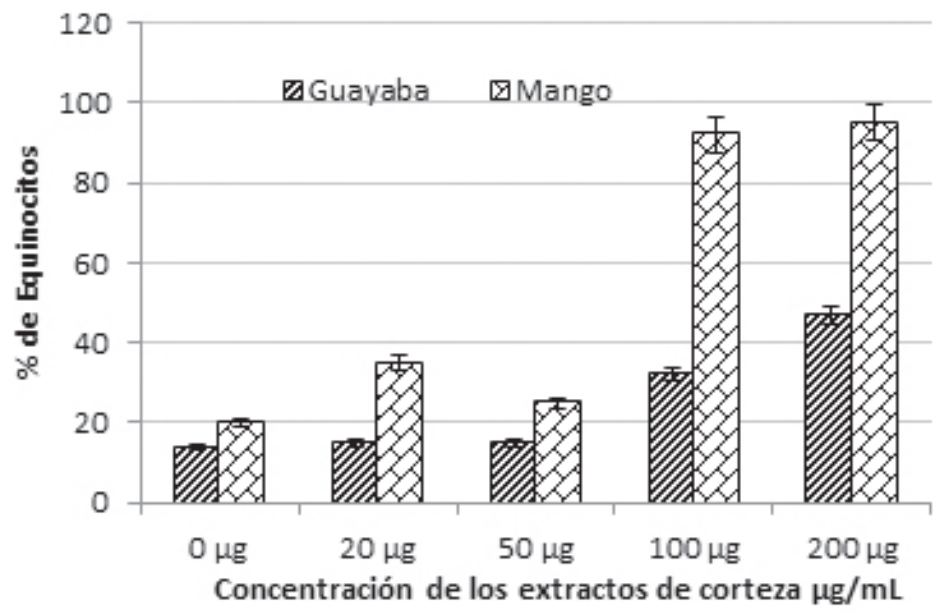

Figura 3. Porcentaje de equinocitos presentada en eritrocitos tratados con los extractos de corteza de mango y de guayaba. Los resultados son presentados como la media más o menos la desviación estándar de tres experimentos independientes. $\mathrm{p}$ 0,17 no hubo significancia estadística entre los extractos evaluados. 
de sodio, inducen alteraciones morfológicas (equinocitos) in vivo en eritrocitos maduros de peces, a concentraciones de 1,5-3pmm en bagres (Zeni et al. 2002).

Los eritrocitos pueden cambiar su forma normal a la forma de equinocitos o estomatocitos, lo cual, depende de factores citoplasmáticos, entre ellos el pH (Gedde et al. 1997). Las altas concentraciones de flavonoides hallados en frutas mango (García Bacallao et al. 2001), hojas de guayaba (Rodríguez et al. 2013) , granada (Castro et al. 1996). Flavonoides obtenidos de maqui (Aristotelia chilensis) con propiedades antioxidantes son inductores de equinocitos (Suwalsky et al. 2008).

El mayor número de equinocitos se presentó a las mayores concentraciones de 100 y $200 \mu \mathrm{g} / \mathrm{mL}$, de los extractos metanólico total de la corteza de mango y guayaba (Figura 3). Guayaba y mango son frutas tropicales populares en el mundo y el mango se encuentra clasificado en la lista de súper-fruta (Gross, 2009). Ajila \& Prasada (2008) comprobaron que la cáscara de mango contiene compuestos polifenolicos, carotenoides con propiedades antioxidante y efecto protector de membrana. Productos naturales obtenidos de plantas, se han reportado con efecto citotóxico, los cuales, se han utilizado en el tratamiento del cáncer; entre estos compuestos, se han aislado alcaloides, como vincristina y vinblastina aisladas de la Madagascar periwinkle; otros agentes citotóxicos derivados de la naturaleza son los taxanos y las comptothecinas (Laza et al. 2003), por lo tanto, estudiar la toxicidad de los subproductos es necesario, a su vez, que ayuda a conocer el perfil de toxicidad de los extractos y de los productos naturales (Omena et al. 2012).

Los extractos metanólicos total de cortezas de mango y de guayabas verdes no fueron citotóxicos; el porcentaje de muerte celular fue inferior al $20 \%$. Los extractos de cáscaras de mango y de guayaba verde inhibieron la hemólisis de eritrocitos, en presencia de peróxido de hidrógeno.

La inhibición de hemólisis mostrada por estos extractos puede ser debida a la interacción de los componentes bioactivos, tipo flavonoides, compuestos fenólicos aislados de corteza de mango y vitamina C, presentes en los extractos de guayaba. Los extractos de corteza de ambas frutas inhibieron la hemólisis en presencia de $\mathrm{H}_{2} \mathrm{O}_{2}$; la mayor inhibición de la hemólisis inducida fue de $63 \%$, con el extracto de corteza de guayaba, a la concentración de $100 \mu \mathrm{g} / \mathrm{mL}$, seguida por inhibición de $52 \%$ mostrada por el extracto de corteza de mango, a concentración $20 \mu \mathrm{g} / \mathrm{mL}$.

Los datos obtenidos en este estudio mostraron que los extractos poseen baja toxicidad a las concentraciones evaluadas; en general, presentaron un porcentaje de viabilidad entre 75 - 90\%. La hemolisis inducida fue inhibida por am- bos extractos; sin embargo, la concentración de $100 \mu \mathrm{g} / \mathrm{mL}$, mostró la mayor inhibición de la hemolisis. La mayor alteración, a nivel de la membrana eritrocitaria representada por la formación de equinocitos, se observó a las mayores concentraciones evaluadas (100-200 $\mu \mathrm{g} / \mathrm{ml})$, para ambos extractos.

Agradecimientos: A la Universidad de Cartagena, por la financiación del presente trabajo. Conflicto de intereses: El artículo fue preparado y revisado con la participación de todos los autores, quienes declaramos que no existe ningún conflicto de intereses, que ponga en riesgo la validez de los resultados presentados.

\section{BIBLIOGRAFÍA}

1. AJILA, C.; PRASADA RAO, U. 2008. Protection against hydrogen peroxide induced oxidative damage in rat erythrocytes by Mangifera indica L. peel extract. Food Chem. Toxicol. (Estados Unidos). 46(1):303309.

2. ALMEIDA, M.; DE SOUSA, P.; ARRIAGA, Â.; DO PRADO, G.; MAGALHÃES, C.; MAIA, G.; DE LEMOS, T. 2011. Bioactive compounds and antioxidant activity of fresh exotic fruits from northeastern Brazil. Food Res. Int. 44(7):2155-2159.

3. BONARSKA-KUJAWA, D.; PRUCHNIK, H.; OSZMIANSKI, J.; SARAPUK, J.; KLESZCZYNSKA, H. 2010. Changes Caused by Fruit Extracts in the Lipid Phase of Biological and Model Membranes. Food Biophys. 6(1):58-67.

4. CARRILLO-ESPER, R.; CARRILLO-CÓRDOVA, C.; CARRILLO- CÓRDOVA, J.; CARRILLO-CÓRDOVA, L. 2012. Storage- induced morphological changes in erythrocytes. Rev. Invest. Med. Sur Mex. 19(1):10-14.

5. CASTRO, O.; BARRIOS, M.; CHINCHILLA, M.; GUERRERO, O. 1996. Evaluación química y biológica del efecto de extractos de plantas contra. Rev. Biol. Trop. 44(2):361-367.

6. CONTRERAS-CALDERÓN, J.; CALDERÓN-JAIMES, L.; GUERRA-HERNÁNDEZ, E.; GARCÍA-VILLANOVA, B. 2011. Antioxidant capacity, phenolic content and vitamin C in pulp, peel and seed from 24 exotic fruits from Colombia. Food Res. Int. 44(7):2047-2053.

7. CHÁVEZ, R.; PLAZA, A.; L. DE UGAZ, O. 2013. Antioxidantes de origen vegetal. Rev. Quím. 10(1):71-101.

8. CHEN, H.; YEN, G. 2007. Antioxidant activity and free radical- scavenging capacity of extracts from 
guava (Psidium guajava L.) leaves. Food Chem. 101(2):686-694.

9. GAITÁN, R.; DURÁN, M.; FRANCO, L. 2006. Acción Antiinflamatoria preliminar de los Extractos de las Esponjas Marinas Xestospongiaros ariensis y X. próxima utilizando los Modelos Edema Plantar Inducido por Carragenina y Polimorfonuclear Neutrofilo. Act. Biol. 27(1):11-15.

10. GARCÍA BACALLAO, L.; GARCÍA GÓMEZ, L.V.; ROJO DOMÍNGUEZ, D.M.; SÁNCHEZ GARCÍA, E. 2001. Plantas con propiedades antioxidantes. Rev. Cub. Invest. Biomédicas. 20(3):231-235.

11. GARDNER, P.; WHITE, T.; MCPHAIL, D.; DUTHIE, G. 2000. The relative contributions of vitamin $C$, carotenoids and phenolics to the antioxidant potential of fruit juices. Food Chem. 68(4):471-474.

12. GEDDE, M.; DAVIS, D.; HUESTIS, W. 1997. Cytoplasmic $\mathrm{pH}$ and human erythrocyte shape. Biophys. J. 72(3):1234-1246.

13. GOYAL, M.; SINGH, P.; ALAM, A.; DAS, S.K.; IGBAL, M.S; DEY, S.; BINDU, S.; PAL, C.; DAS, S.K.; PANDA, G.; BANDYOPADHYAY, U. 2012. Aryl aryl methyl thio arenes prevent multidrug-resistant malaria in mouse by promoting oxidative stress in parasite. Free Radical Biol. Med. 53(1):129-142.

14. GRINBERG, L.; NEWMARK, H.; KITROSSKY, N.; RAHAMIM, E.; CHEVION, M.; RACHMILEWITZ, E. 1997. Protective effects of tea polyphenols against oxidative damage to red blood cells. Biochem. Pharmacol. (Estados Unidos). 54(9):973-878.

15. GROSS, P. 2009. Superfruits: (Top 20 Fruits Packed with Nutrients and Phytochemicals, Best Ways to Eat Fruits for Maximum Nutrition, and 75 Simple and Delicious Recipes for Overall Wellness). The McGraw- Hill Companies, Inc. Estados Unidos. 221p.

16. GUO, C.; YANG, J.; WEI, J.; LI, Y.; XU, J.; JIANG, Y. 2003. Antioxidant activities of peel, pulp and seed fractions of common fruits as determined by FRAP assay. Nutr. Res. 23(12):1719-1726.

17. JIMÉNEZ-ESCRIG, A.; RINCÓN, M.; PULIDOR, R.; SAURA-CALIXTO, F. 2001. Guava fruit (Psidium guajava L.) as a new source of antioxidant dietary fiber. J. Agr. Food Chem. 49(11):5489-5493.

18. KAUR, C.; KAPOOR, H.C. 2001. Antioxidants in fruits and vegetables-the millennium's health. Int. J. Food Sci. Technol. 36(7):703-725.

19. KOIKE, S.; SUBBARAO, K.; DAVIS, R.M.; TURINI, T. 2003. Vegetable diseases caused by soilborne pathogens: UCANR Publications. Disponible desde Internet en: http://ucanr.org/freepubs/docs/8099.pdf (con acceso 27/04/13).

20. LABIENIEC, M.; GABRYELAK, T. 2005. Measurement of DNA damage and protein oxidation after the incubation of B14 Chinese hamster cells with chosen polyphenols. Toxicol. letters 155(1):15-25.

21. LAZA, D.; RODRÍGUEZ, L.; SARDIÑA, G. 2003. Descubrimiento y desarrollo de agentes anticancerígenos derivados de plantas medicinales. Rev. Cub. Plantas Medicinales. 8(3):e12.

22. MARTÍNEZ, A.; REYES, I.; REYES, N. 2007. Citotoxicidad del glifosato en células mononucleares de sangre periférica humana. Biomédica. 27(4):594-604.

23. MOHANDAS, N.; CHASIS, J.; SHOHET, S. 1983. The influence of membrane skeleton on red cell deformability, membrane material properties, and shape. Semin. Hematol. 20(3):225-242.

24. OKONOGI, S.; DUANGRAT, C.; ANUCHPREEDA, S.; TACHAKITTIRUNGROD, S.; CHOWWANAPOONPOHN, S. 2007. Comparison of antioxidant capacities and cytotoxicities of certain fruit peels. Food Chem. 103(3):839-846.

25. OMENA, C.; VALENTIM, I.; GUEDES, G.; RABELO, L.; MANO, C.; BECHARA, E. 2012. Antioxidant, anti-acetyl cholinesterase and cytotoxic activities of ethanol extracts of peel, pulp and seeds of exotic Brazilian fruits: Antioxidant, anti-acetyl cholinesterase and cytotoxic activities in fruits. Food Res. Int. 49(1):334-344.

26. PERCIVAL, S.; TALCOTT, S.; CHIN, S.; MALLAK, A.; LOUNDS-SINGLETON, A.; PETTIT-MOORE, J. 2006. Neoplastic transformation of BALB/3T3 cells and cell cycle of HL-60 cells are inhibited by mango (Mangifera indica L.) juice and mango juice extracts. J. Nutr. 136(5):1300-1304.

27. PINELL, G.; TERÁN, C.; GUARACHI, E.; ILLANES, J. 2009. Actividad citotóxica in vitro en líneas celulares y células de sangre periférica humana de los alcaloides totales de corteza de Galipea longiflora (Evanta). Rev. Bol. Quim. 26(2):96-100. 
28. PRASAD, S.; KALRA, N.; SHUKLA, Y. 2007. Induction of apoptosis by lupeol and mango extract in mouse prostate and LNCaP cells. Nutr. Cancer. 60(1):120130.

29. RINCÓN, A.; VÁSQUEZ, A.; PADILLA, F. 2005. Composición química y compuestos bioactivos de las harinas de cáscaras de naranja (Citrus sinensis), mandarina (Citrus reticulata) y toronja (Citrus paradisi) cultivadas en Venezuela. Arch. Latinoam. Nutr. 55(3):305310. Disponible desde Internet en: http://www.scielo. org.ve/scielo.php?script $=$ sci_arttext\&pid = S0004-

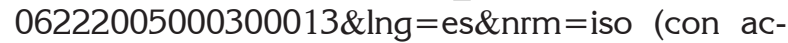
ceso 27/04/13).

30. RODRÍGUEZ, R.; LAFOURCADE, A.; PÉREZ, L. 2013. Hojas de Psidium guajava L. Rev. Cub. Farm. 47(1):127-135.

31. RODRÍGUEZ, J.; MENÉNDEZ, J.; TRUJILLO, Y. 2001. Radicales libres en la biomedicina y estrés oxidativo. Rev. Cub. Med. Militar. 30(1):15-20.

32. SLAMEÑOVÁ, D.; HORVOTOVÁ, E.; WSÓLOVÁ, L.; SRAMKOVÁ, M.; NAVAROVÁ, J. 2009. Investigation of anti-oxidative, cytotoxic, DNA- damaging and DNA-protective effects of plant volatiles eugenol and borneol in human-derived HepG2, Caco-2 and VH10 cell lines.Mutation Research/Genetic Toxicol. Environ. Mutagen. 677(1-2):46-52.

33. SMITH, J.E. 1987. Erythrocyte membrane: structure, function, and pathophysiology. Vet. Path. 24(6):471476.

34. SOONG, Y.Y.; BARLOW; P.J. 2004. Antioxidant activity and phenolic content of selected fruit seeds. Food Chem. 88(3):411-417.
35. STROBER, W. 2001. Trypan blue exclusion test of cell viability. Curr. Protocols Immunol. A. 3B. 1-A. 3B. 2.

36. SUN, J.; CHU, Y.F.; WU, X.; LIU, R. 2002. Antioxidant and antiproliferative activities of common fruits. J. Agr. Food Chem. 50(25):7449-7454.

37. SUWALSKY, M.; VARGAS, P.; AVELLO, M.; VILLENA, F.; SOTOMAYOR, C.P. 2008. Human erythrocytes are affected in vitro by flavonoids of Aristotelia chilensis (Maqui) leaves. Int. J. Pharmaceut. 363(1-2):85-90.

38. UGARTONDO, V.; MITJANS, M.; LOZANO, C.; TORRES, J.L.; VINARDELL, M.P. 2006. Comparative study of the cytotoxicity induced by antioxidant epicatechin conjugates obtained from grape. J. Agr. Food Chem. 54(18):6945-6950.

39. VENEREO, J.R. 2002. Daño oxidativo, radicales libres y antioxidantes. Rev. Cub. Med. Militar. 31(2):126-133.

40. WANG, Y.; HUANG, S.; SHAO, S.; QIAN, L.; XU, P. 2012. Studies on bioactivities of tea (Camellia sinensis L.) fruit peel extracts: Antioxidant activity and inhibitory potential against $\alpha$-glucosidase and $\alpha$-amylase in vitro. Industr. Crops Prod. 37(1):520-526.

41. ZENI, C.; BOVOLENTA, M.R.; STAGNI, A. 2002. Occurrence of echinocytosis in circulating RBC of black bullhead, Ictalurus melas (Rafinesque), following exposure to an anionic detergent at sublethal concentrations. Aquat. Toxicol. 57(4):217-224.

Recibido: Mayo 5 de 2013

Aceptado: Octubre 8 de 2013

\section{Como citar:}

Durán, M.; Montero, P.; Marrugo, Y. 2013. Extractos metanólicos de corteza de guayaba (Psidium guajava L.) y mango (Mangifera indica L.): efecto citotóxico, antihemolítico y en la morfología de membrana de eritrocitos. Rev. U.D.C.A Act. \& Div. Cient. 16(2): 327-334. 